\title{
PENERAPAN APLIKASI MACRO UNTUK SURAT MASUK DAN SURAT KELUAR DALAM MENINGKATKAN PELAYANAN DESA
}

\author{
Maulana Dwi Sena ${ }^{1}$, Risnawati, Rohminatin ${ }^{2}$ \\ ${ }^{1,2)}$ Program Studi Sistem Informasi, STMIK Royal Kisaran \\ e-mail : rohminatin2019@gmail.com
}

\begin{abstract}
Abstrak
Kegiatan Pengabdian kepada Masyarakat berupa pelatihan dalam pembuatan aplikasi macro untuk surat masuk dan keluar dalam meningkatkan pelayanan desa khususnya bagian administrasi di bagian pengolahan data ini bertujuan untuk memberikan pengetahuan dan keterampilan, yang diharapkan dapat menghasilkan perubahan pengetahuan, keterampilan dan sikap dari pihak balai desa. Khalayak sasaran dalam kegiatan Pengabdian kepada Masyarakat ini adalah seluruh perangkat desa tanah rakyat Kecamatan Pulo Bandring. Kegiatan penerapan aplikasi macro ini adalah untuk meningkatkan keterampilan penggunaan macro VBA yang digunakan untuk proses pembuatan data surat masuk dan keluar yang ada di balai desa. Metode yang digunakan adalah ceramah, demonstrasi aplikasi yang akan digunakan dan tanya jawab. Metode ceramah digunakan untuk menjelaskan konsep tentang aplikasi yang digunakan yaitu Macro VBA. Metode demonstrasi untuk menunjukkan suatu proses kerja yaitu tahapan-tahapan dari setiap kegiatan dan mempraktikkannya, sementara metode tanya jawab untuk memberi kesempatan para peserta berkonsultasi dalam mengatasi kendala yang terjadi dalam penerapan dan penggunakan aplikasi.Manfaat yang diperoleh dari kegiatan ini antara lain dapat meningkatkan pengetahuan perangkar desa agar lebih profesional dalam membuat surat masuk dan keluar secara efektif dan efisien dalam penguasan IPTEKS, sehingga dapat mempermudah proses penerapan aplikasinya.
\end{abstract}

Kata Kunci : Aplikasi Macro VBA, Surat Masuk dan Keluar, Administrasi.

\begin{abstract}
Community Service Activities in the form of training in making macro applications for incoming and outgoing letters in improving village services, especially the administration section in the data processing section, aim to provide knowledge and skills, which are expected to result in changes in knowledge, skills and attitudes of the village hall. The target of this Community Service activity is all village apparatus of the people's land, Pulo Bandring sub-district. The activity of implementing this macro application is to improve the skills of using VBA macros which are used for the process of creating data for incoming and outgoing mail in the village hall. The methods used are lectures, demonstrations of applications to be used and questions and answers. The lecture method is used to explain the concept of the application used, namely VBA Macros. The demonstration method is to show a work process, namely the stages of each activity and practice it, while the question and answer method is to give participants the opportunity to consult in overcoming obstacles that occur in the application and use of the application. The benefits obtained from this activity include increasing knowledge of operators. villages to be more professional in making incoming and outgoing letters effectively and efficiently in mastering science and technology, so as to facilitate the process of implementing the application.
\end{abstract}

Keywords : VBA Macro Application, Incoming and Outgoing Mail, Administration.

\section{PENDAHULUAN}

Kemajuan teknologi komputer sebagai pendukung pemrosesan data dan sistem informasi telah menjadi kebutuhan pokok sebuah instansi maupun perusuhaan. Instansi maupun perusahaan jasa pelayanan yang memberikan pelayanan kepada masyarakat, sangat membutuhkan kecepatan pelayanan informasi sehingga dapat memberikan pelayanan yang optimal kepada masyarakat, salah satunya adalah balai desa tanah rakyat Kecamatan Pulo Bandring.

Balai Desa adalah sebuah Instansi Pemerintahan tempat berkumpulnya warga dalam bermusyawarah yang berada pada tingkat paling bawah, dalam permendagri No. 84 tahun 2015, yang menyatakan bahwa 
pemerintah desa menyelenggarakan urusan pemerintahan dan kepentingan masyarakat setempat dalam sistem pemerintahan negara kesatuan republik. Balai desa yang terletak di Tanah rakyat Kecamatan Pulo Bandring. Perangkat Desa adalah unsur staf yang membantu Kepala Desa dalam penyusunan kebijakan dan koordinasi yang diwadahi dalam Sekretariat Desa, dan unsur pendukung tugas Kepala Desa dalam pelaksanaan kebijakan yang diwadahi dalam bentuk pelaksana teknis dan unsur kewilayahan.

Perangkat desa yang kesehariannya memberikan pelayanan kepada masyarakat, merupakan tolok ukur berkembangnya desa. Kualitas pelayanan kepada masyarakat merupakan hal pokok yang senantiasa menjadi titik sentral setiap desa, Pada balai desa tanah rakyat mengalami kesulitan dalam pembuatan surat masuk dan keluar yang hanya menggunakan penulisan dan pada buku besar. Bagaimana agar sesuatu yang menyangkut tentang data atau keterangan tersebut mempunyai kegunaan atau nilai tertentu, sehingga arsip yang diperlukan sangat mudah untuk ditemukan, oleh sebab itu perangkat desa membutuhkan suatu sistem penginputan data surat masuk dan keluar yang menggunakan database agar dapat tersimpan dengan rapi.

Sebagai sebuah pelayanan desa dibidang pemerintahan yang memberikan palayanan kepada masyarakat setiap harinya, terlihat bahwa balai desa tanah rakyat ini masih memiliki masalah dalam penerapan surat masuk dan keluar. Penerapan surat masuk dan keluar yang digunakan masih dalam bentuk metode konvensional tanpa menggunakan database sehingga jika terjadi kesalahan berulang, maka wajib untuk mengulang kembali penulisan dari awal. Setelah melihat kondisi tersebut, maka dilakukan kegiatan pengabdian kepada masyarakat dengan memberikan pelatihan penerapan aplikasi macro untuk surat masuk dan keluar dalam meningkatkan pelayanan desa.

\section{METODE}

Metode pelaksanaan dalam pengabdian masyarakat ini adalah bentuk pelatihan di dalam ruangan dengan metode ceramah, diskusi dan tanya jawab serta praktek pembukuan secara langsung. Jadwal pelaksanaan pelatihan pengelolaan pembukuan dapat dilihat pada tabel berikut:

Tabel 2. Jadwal Kegiatan Pengabdian Masyarakat

\begin{tabular}{|c|c|c|}
\hline Waktu & Tema & Pemandu \\
\hline \multicolumn{3}{|l|}{ Senin, 1 Februari 2021} \\
\hline 08.00 WIB - 9.00 WIB & Pembukaan & Kepala Desa \\
\hline $09.00 \mathrm{WIB}-10.00 \mathrm{WIB}$ & $\begin{array}{l}\text { Pengenalan Ms. Excel dan } \\
\text { Excel Macro VBA }\end{array}$ & $\begin{array}{l}\text { Maulana Dwi Sena, } \\
\text { S.Kom., M.Kom }\end{array}$ \\
\hline $10.00 \mathrm{WIB}-11.00 \mathrm{WIB}$ & $\begin{array}{l}\text { Dasar-Dasar Excel Macro } \\
\text { VBA }\end{array}$ & Tim PkM \\
\hline $11.00 \mathrm{WIB}-12.00 \mathrm{WIB}$ & Tanya jawab & Tim PkM \\
\hline \multicolumn{3}{|l|}{ Selasa, 2 Februari 2021} \\
\hline $08.00 \mathrm{WIB}-9.30 \mathrm{WIB}$ & $\begin{array}{l}\text { Praktek Membuat Aplikasi } \\
\text { Data Pelanggan }\end{array}$ & Tim PkM \\
\hline 09.30 WIB - $11.30 \mathrm{WIB}$ & $\begin{array}{l}\text { Praktek Input Data } \\
\text { Pelanggan }\end{array}$ & Tim PkM \\
\hline $11.30 \mathrm{WIB}-12.00 \mathrm{WIB}$ & Tanya jawab & Tim PkM \\
\hline
\end{tabular}

\section{HASIL DAN PEMBAHASAN}

Pelaksanaan kegiatan pengabdian ini berjalan sesuai dengan rencana yang telah ditetapkan. Hal ini disebabkan oleh adanya kerjasama yang baik antara tim pelaksana pengabdian dengan Perangkat Balai Desa Tanah rakyat yang terlibat. Pada saat pelaksanaan perangkat Balai Desa yang mengikuti kegiatan pelatihan tersebut dengan semangat dan antusiasme yang tinggi. Hal ini terbukti dengan adanya perhatian dan ketekunan para peserta dalam menjalankan semua instruksi yang diberikan oleh tim pelaksana. Pada 
waktu pelatihan berlangsung, peserta juga terlihat aktif dalam menanyakan segala hal yang belum mereka ketahui

Adapun hasil yang dicapai dalam pelatihan ini adalah peserta pelatihan yang merupakan Perangkat desa dapat menerapkan surat masuk dan keluar menjadi lebih efektif dan efisien karena tidak perlu lagi menggunakan word dan buku ekspedisi untuk mencatat. Selain itu, pelatihan ini memberikan manfaat kepada seluruh perangkat desa untuk bagaimana memanfaatkan teknologi khususnya komputer dengan lebih bijak lagi.

Materi dalam pelatihan ini dibuat sesuai dengan kebutuhan dalam mengolah data pelanggan dengan cepat menggunakan aplikasi macro excel. Bagi perangkat desa yang sudah memiliki keterampilan dalam menggunakan komputer dan menggunakan Ms. Excel dalam proses penerapan, maka mereka akan lebih mudah menguasai macro excel yang diajarkan oleh narasumber. Tetapi sebaliknya, bagi yang masih belum terbiasa menggunakan penginputan yang ada di excel yang diberikan, maka mereka lebih lambat dalam proses pengolahan data tersebut karena sebelum memasukkan inputan yang diinginkan maka mereka terlebih dahulu harus memahami macro excel untuk membuat aplikasi dan mengolah data tersebut. Bagi yang belum terbiasa, otomatis hal ini dapat memperlama proses penginputan data.

Adapun contoh penerapan aplikasi macro surat masuk dan keluar pada Balai Desa Tanah rakyat dalam pelatihan dapat dilihat pada gambar di bawah ini:

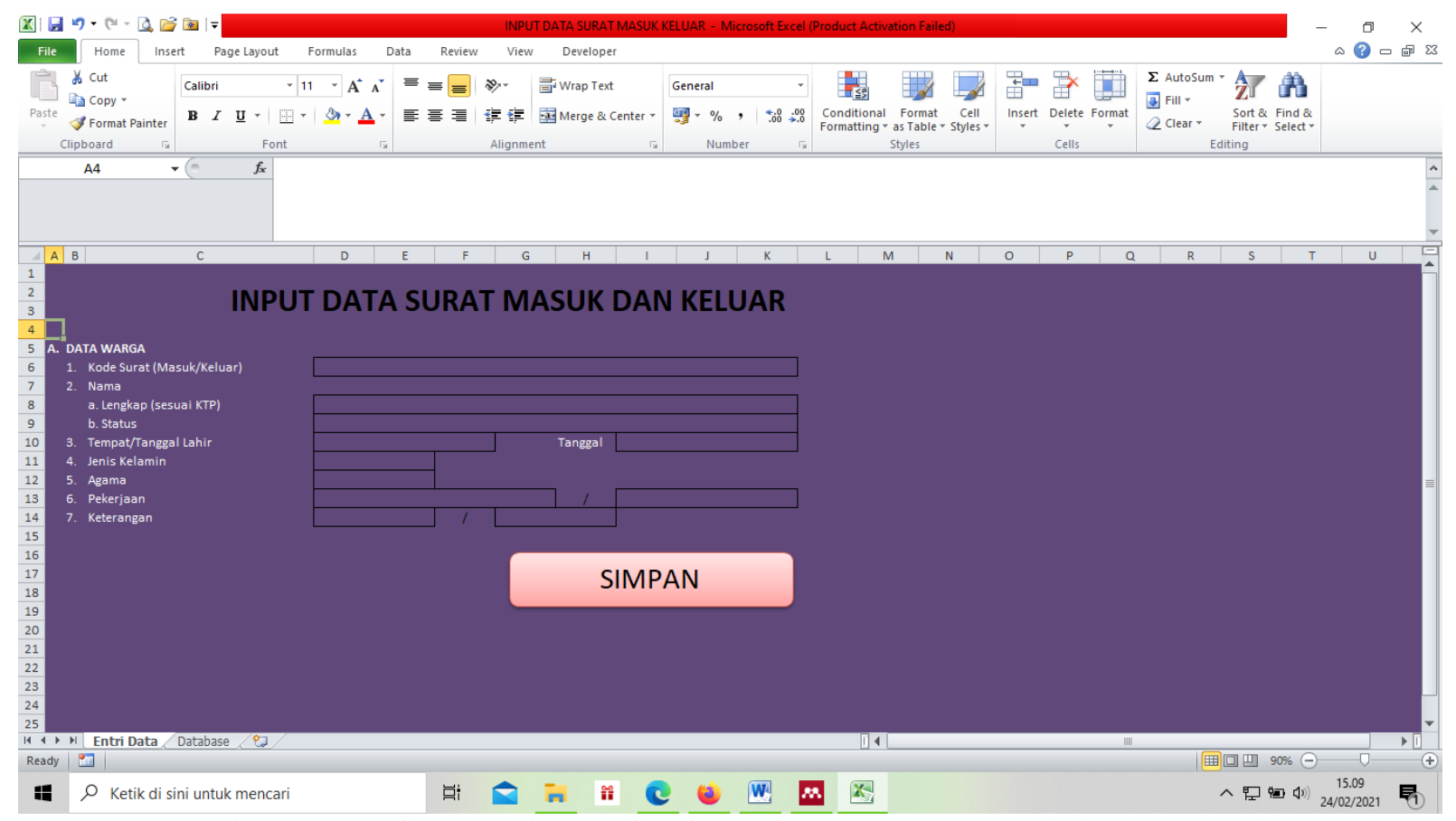

Gambar 1. Tampilan Gambar Aplikasi Penginputan Surat Masuk dan Surat Keluar 


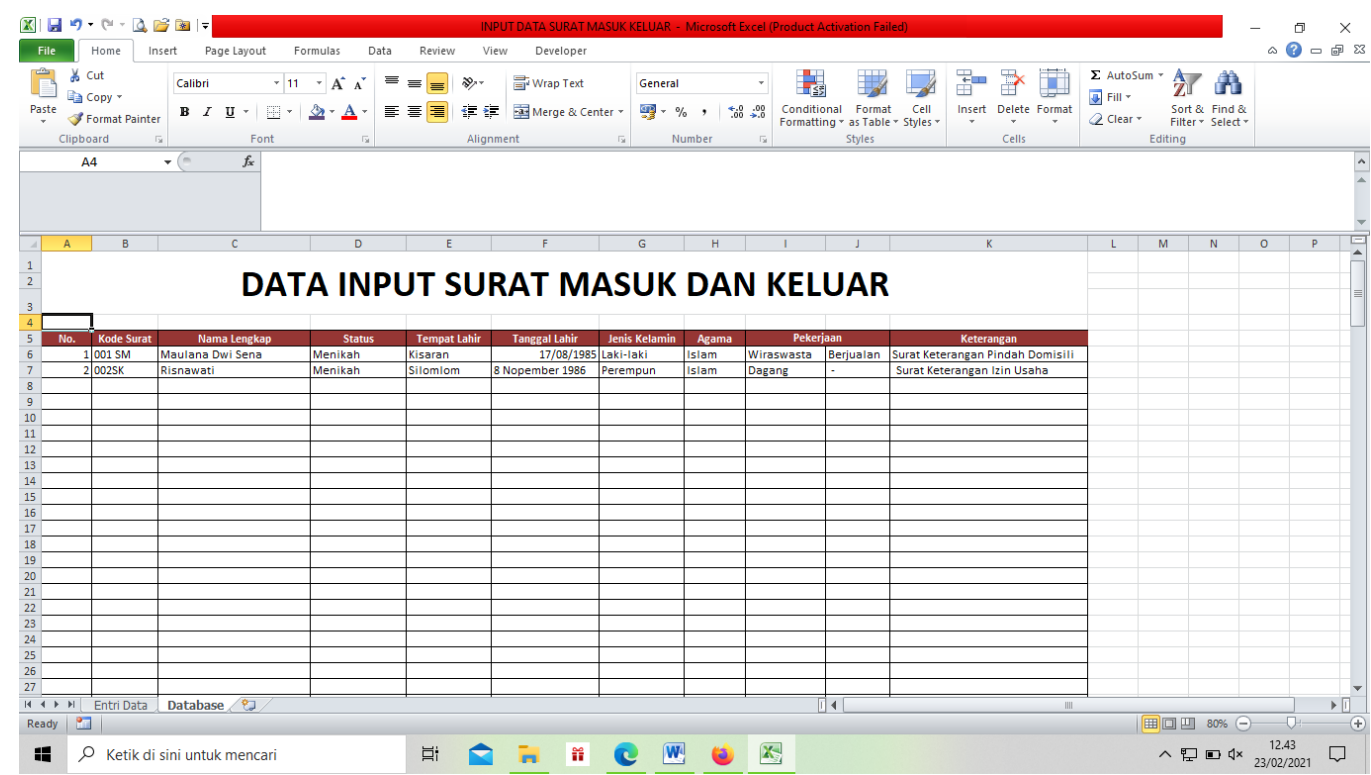

Gambar 2. Tampilan Penyimpanan Data Surat Masuk dan Surat Keluar

\section{SIMPULAN}

Kesimpulan dari Kegiatan Pengabdian kepada masyarakat yang telah dilaksanakan bahwa kegiatan yang telah dilakukan direspon sangat baik oleh para peserta dimana peserta merupakan seluru perangkat desa. Penerapan aplikasi yang telah diajarkan kepada peserta sangat membantu dalam penanganan surat masuk dan surat keluar serta meningkatkan pelayanan kepada masyarakat desa.

\section{SARAN}

Diharapkan untuk kegiatan pengabdian selanjutnya dapar melakukan kegiatan sejenis yang terfokus kepada pengambangan kualitas sumber daya manusia dengan memberikan pelatihan tidak hanya dalam proses penerapan aplikasi data surat masuk dan keluar saja, akan tetapi pembuatan sistem informasi data yang lain juga.

\section{UCAPAN TERIMAKASIH}

Terimakasih kami ucapkan kepada Bapak Kepala Desa tanah rakyat beserta seluruh perangkat desa atas sambutan positifnya dalam pelaksanaan kegiatan masyarakat ini serta terimakasih kami ucapkan kepata STMIK Royal Kisaran yang telah membantu terlaksananya kegiatan ini.

\section{DAFTAR PUSTAKA}

K. Barat (2019),“Peningkatan Keterampilan Penggunaan Macro VBA,” pp. 29-37

B. Anoraga, P. Nandari Bambang Eka, and . Sukadi, "Aplikasi Sistem Pengelolaan Surat Pada Kantor Desa Jetis Lor," Speed - Indones. J. Comput. Sci., vol. 11, no. 2014: IJCSS-Accepted Paper, pp. 6671, 2014, [Online]. Available: http://ejournal.unsa.ac.id/index.php/speed/article/view/892.

H. Sucipto, A. Mujianto, C. Mahsuri, M. Ali, and Mahfudiyanto (2020), "Implementasi Aplikasi E-Surat pada Perangkat Desa di Desa Mentrus Kudu Jombang," J. Abidumasy, vol. 01, pp. 34-41,

S. Saifullah and B. M. Akbar (2020) "PELATIHAN E-LEARNING MENGGUNAKAN GOOGLE CLASSROOM BAGI GURU MA RADEN FATAH PRAMBANAN,” vol. 4, no. 1, pp. 93-103,

P. T. Bank and M. Cab (2019), "Implementasi Macro Excel ( VBA ) Sebagai Sistem Informasi Registrasi Dan Monitoring Talangan Haji Pada," vol. 1, no. 1, pp. 48-67,

R. S. Samosir, M. Rusli, E. Syahrani, and J. S. Informasi (2019), "PKM PENINGKATAN KOMPETENSI SISWA SMK ABDI NEGARA MELALUI PELATIHAN MACRO UNTUK," vol. 2, no. 2, pp. 6-14 